\title{
The interarytenoid fold of the larynx: Is it immune to cancer?
}

\author{
Original Mohamed Rifai; AbdelRahman Younes and Hazem M. Abdel Tawab \\ Article \\ Otorhinolaryngology Department, Faculty of Medicine, Cairo University, Egypt.
}

\begin{abstract}
Introduction: The posterior commissure (PC), or interarytenoid fold of the larynx (IAFL), is an uncommon site for glottic carcinoma. The aim of this study is to confirm the absolute rarity of the IAFL's involvement with malignancy. Materials and Methods: A retrospective case-control study which included data from 437 laryngectomies were studied. The data were collected from the medical records of 394 patients with cancer larynx, aged 42-83 years in the time period from 2013 till 2017.

Results: The larynges of 385 males and 9 females were studied. . The most common presenting symptoms were voice change and difficulty breathing. In all cases, there was no posterior interarytenoid involvement even from extensive lesions.

Conclusion: Involvement of the posterior commissure, or IAFL, is almost absent in cancer of the larynx compared to other laryngeal sites. This observation warrants further study to delineate the structural difference between the IAFL and other laryngeal sub sites.
\end{abstract}

Key Words: Arytenoid, larynx, laryngectomies.

Received: 18 November 2018, Accepted: 02 January 2019

Corresponding Author: Hazem M. Abdel Tawab, MD of Otorhinolaryngology, Faculty of Medicine, Cairo University, Egypt and Senior Specialist of Otorhinolaryngology, Sultan Qaboos hospital, Salalah, Oman, Tel.: 0096891128430, E-mail: hazemabdeltawwab77@yahoo.com

ISSN: 2090-0740, November 2018, Vol.19, No. 3

\section{INTRODUCTION}

The posterior commissure (PC) of the larynx is described as the plica interarytenoidea, the interarytenoid fold of the larynx (IAFL), or the mucosal fold extending across the midline between the arytenoid cartilages at the base of the interarytenoid notch, forming the posteromedian portion of the laryngeal inlet ${ }^{[1,2]}$. There is no general agreement as to whether the vocal process of the arytenoids is part of the PC.

Cancer of the larynx that primarily originates in or extends to the $\mathrm{PC}$ is infrequently encountered even in extensive laryngeal carcinoma.

A literature search found few articles concerning cancer affecting the PC. Initially, two case reports were published in $1959^{[3]}$. Sixty PC tumors were described in $2003^{[4]}$, and a few years later in 2009, a series of 40 patients aged over 48 years and diagnosed with T1 PC carcinoma were reported ${ }^{[5]}$.

In all the reviewed articles, the vocal process of the arytenoid was included as part of the PC. Whether the arytenoids were primarily involved by de novo carcinoma or, by extension, from glottic carcinoma was not clearly defined.
This current study was based on personal observations regarding the plica interarytenoidea. To avoid debate regarding the $\mathrm{PC}$, the study focused solely on the plica interarytenoidea.

\section{MATERIALS AND METHODS}

Medical records of 394 patients who suffered from carcinoma of the larynx were retrospectively surveyed. Diagnosis was confirmed by histological analysis. All patients were treated with curative intent at our department of Otorhinolaryngology. The study's data included medical records, flexible laryngoscopy images, direct laryngoscopy lesion descriptions, and pathological reports of patients diagnosed and treated between July 2013 and June 2017.

\section{RESULTS}

Three hundred and ninety-four patients had laryngectomies (75 partial laryngectomy and 319 total laryngectomies [TLs]) as the primary treatment. Thirtysix patients (4 T2 and $32 \mathrm{~T} 3$ ) had TLs for recurrence after being initially treated with radiotherapy. Tumors were classified according to the TNM system of the American Joint Committee on Cancer ${ }^{[6]}$. 
Recurrent cancer of the larynx was encountered in seven other patients. Two had recurrences following transoral laser surgical resection for $\mathrm{T} 1$ cancer of the larynx, and five had recurrences after supracricoid laryngectomy for $\mathrm{T} 3$ lesions.

Four hundred and thirty-seven postoperative specimens were studied. The data from the 43 patients with recurrent lesions were studied prior to and following surgery. The interarytenoid fold was not involved by malignancy in any of these patients.

\section{DISCUSSION}

The IAFL mucosa was retrospectively studied in 480 larynges of patients who suffered from cancer of the larynx. The IAFL was free of cancer invasion in all studied larynges.

An interesting retrospective study included 46 patients with lesions limited to the posterior glottis between 2008 and 2011. Forty-one of the cases were strictly benign lesions and only two of the 46 patients proved to be malignant, one with carcinoma in situ and one with invasive squamous cell carcinoma ${ }^{[7]}$.

One hundred and two cases of malignant invasion of the PC have been reported in previous studies over a period of 48 years. In these studies, the vocal process of the arytenoid was included as part of the PC. Despite this, the small number of cases with reported malignancy of the PC confirms the relative immunity of this posteriorly located area of the larynx to malignancy.

In this study, IAFL was not involved in all laryngeal specimens obtained from the initial or post recurrence surgical treatment for cancer larynx. In view of common exposure of the IAFL to possible GERD and irritation caused by smoking, the conclusion drawn from this report warrants that the IAFL deserve serious attention and research.

\section{CONCLUSION}

Involvement of the posterior commissure (interarytenoid fold of the larynx) compared to other sites is rare in cancer larynx. Further study of this anatomical subsite of the larynx is essential to delineate the structural difference between it and other laryngeal subsites.

\section{CONFLICTS OF INTEREST}

No conflicts of interest.

\section{FINANCIAL SUPPORT}

No financial support.

\section{REFERENCES}

1. Farlex Partner Medical Dictionary. Posterior commissure of the larynx, http://, medical dictionary. The free dictionary.com/posterior+commissure + of + the+larynx; 2012 [accessed 25.05.17].

2. Mosby's Medical Dictionary, 8th edition. Posterior commissure of the larynx, http://medical dictionary. The free dictionary.com/posterior + commissure + of + the+ larynx; 2009 [accessed 25.05.17].

3. Omar H, Shaheen, OH. Two Cases of Laryngeal Carcinoma at the Posterior Commissure. The Journal of Laryngology \& Otology 1959; 12: 838-842.

4. Rucci L, Bocciolini C, Romagnoli P, Olofsson J. Risk factors and prognosis of anterior commissure versus posterior commissure T1-T2 glottic cancer. Ann Otol Rhinol Laryngol 2003; 112: 223-229.

5. Shvero J, Itzhak SI, Aviram M, Thomas S, Benny N, Rumelia K, Tuvia H. T1 Glottic Carcinoma Involving the Posterior Commissure. Laryngoscope 2009; 119:1116-1119.

6. Shoffel-Havakuk H, Halperin D, Yosef L, Feldberg E, Lahav Y. Lesions of the Posterior Glottis: Clinical and Pathologic Considerations and Treatment Outcome. J Voice 2014; 28:263-e1.

7. American Joint Committee on Cancer. Manual for staging of cancer. 3rd ed. Philadelphia, PA: JB Lippincott; 1988. 